\title{
On the Uncertainty of High-Resolution Hourly Quantitative Precipitation Estimates in California
}

\author{
JANICE L. BYTHEWAY \\ Cooperative Institute for Research in Environmental Sciences, University of Colorado Boulder, and \\ Physical Sciences Laboratory, NOAA/Earth System Research Laboratory, Boulder, Colorado \\ Mimi Hughes, Kelly Mahoney, AND RoB Cifelli \\ Physical Sciences Laboratory, NOAA/Earth System Research Laboratory, Boulder, Colorado
}

(Manuscript received 23 July 2019, in final form 5 February 2020)

\begin{abstract}
The Bay Area of California and surrounding region receives much of its annual precipitation during the October-March wet season, when atmospheric river events bring periods of heavy rain that challenge water managers and may exceed the capacity of storm sewer systems. The complex terrain of this region further complicates the situation, with terrain interactions that are not currently captured in most operational forecast models and inadequate precipitation measurements to capture the large variability throughout the area. To improve monitoring and prediction of these events at spatial and temporal resolutions of interest to area water managers, the Bay Area Advanced Quantitative Precipitation Information project was developed. To quantify improvements in forecast precipitation, model validation studies require a reference dataset to compare against. In this paper we examine 10 gridded, high-resolution $(\leq 10 \mathrm{~km}$, hourly) precipitation estimates to assess the uncertainty of high-resolution quantitative precipitation estimates (QPE) in areas of complex terrain. The products were linearly interpolated to 3-km grid spacing, which is the resolution of the operational forecast model to be validated. Substantial differences exist between the various products at accumulation periods ranging from hourly to annual, with standard deviations among the products exceeding $100 \%$ of the mean. While the products seem to agree fairly well on the timing of precipitation, intensity estimates differ, sometimes by an order of magnitude. The results highlight both the need for additional observations and the need to account for uncertainty in the reference dataset when validating forecasts in this area.
\end{abstract}

\section{Introduction}

Accurate estimates of precipitation in California are necessary because the state generally receives most of its annual precipitation during a few significant storms that occur during the cool season, often associated with atmospheric rivers (ARs) (Dettinger et al. 2011; Ralph et al. 2006, 2013; Neiman et al. 2008; Lamjiri et al. 2017). This precipitation must be managed in such a way that it can be stored and released for use throughout the year for irrigation, recreation, residential needs, and ecological conservation (Dettinger et al. 2011; Kingsmill et al. 2006). Additionally, it is important to accurately measure and predict the precipitation that occurs with these

Corresponding author: Janice L. Bytheway, janice.bytheway@ noaa.gov storms in order to enact flood control procedures and prevent storm sewer system backups.

Because of the need for accurate forecasts of precipitation to force hydrologic models and for stormwater utilities to prepare for the possibility of heavy precipitation, a partnership between San Francisco Bay Area water entities and the National Oceanic and Atmospheric Administration (NOAA) called the Bay Area Advanced Quantitative Precipitation Information (AQPI) project was developed. The AQPI project seeks to provide improved monitoring and forecasting of precipitation processes, streamflow, and coastal flooding for the Bay Area and surrounding region (Fig. 1) at high spatial and temporal resolution. The project includes the installation of a number of gap-filling X-band dualpolarization radars that can observe precipitation in areas that are a significant distance from the nearest 


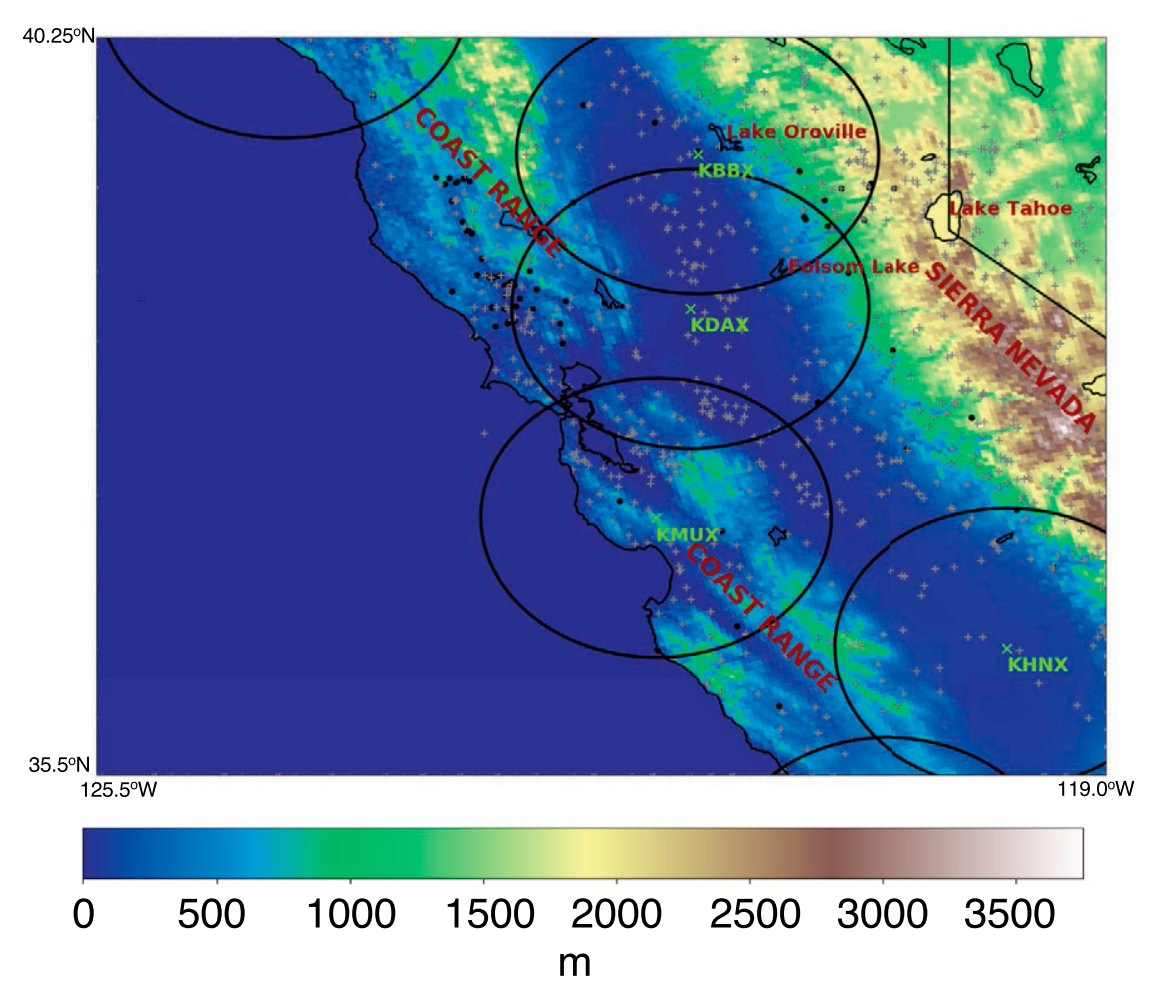

FIG. 1. The AQPI domain, with terrain shaded. Locations of HADS (gray +) and HMT (black dots) gauges are shown, as well as locations of operational WSR-88D radars in the domain (green $\mathrm{x}$ ). The 100-km range rings of radars inside and within $100 \mathrm{~km}$ outside the domain are also shown (circles). Specific locations cited in the text are labeled for reference.

National Weather Service (NWS) operational radar (WSR-88D), or where the operational radar beam is blocked by the complex terrain in the area. Additional surface measurements of precipitation, streamflow, and soil moisture are also included, and will be used to initialize and validate forecasts produced for the region (https://www.esrl.noaa.gov/psd/aqpi/).

The Bay Area of California and surrounding areas are uniquely challenging for quantitative precipitation estimates (QPE). The complex terrain of both the Coastal Ranges and the Sierra Nevada (Fig. 1) results in many regions where the lowest beams of the operational NEXRAD radars are blocked or overshoot shallow precipitation. In a region that frequently experiences shallow stratiform precipitation, this can result in precipitation occurring entirely beneath the lowest available radar beam going unobserved. The complex terrain also inhibits in situ measurement by gauges, which are typically placed closer to the valleys where access and infrastructure are more readily available (Ebert et al. 2007; Henn et al. 2018). Orographic enhancement by the terrain further complicates QPE, creating highly heterogeneous precipitation fields. QPE retrieved from satellite-based observations can provide estimates where ground-based radar and gauges are unavailable, but are also subject to many uncertainties (Bartsotas et al. 2018; Hirpa et al. 2010; Ebert et al. 2007; Tian and Peters-Lidard 2010; Sun et al. 2018). Despite the challenges to observing precipitation in this region, many high-resolution ( $\leq 10 \mathrm{~km}$, hourly to subhourly) gridded precipitation products are available that can provide QPE in the AQPI domain.

In this paper we evaluate these various products to attempt to understand the level of uncertainty in highresolution QPE in this region. Many previous studies have assessed precipitation uncertainty from a variety of gridded products in regions of complex terrain at lower spatial and/or temporal resolution (Bartsotas et al. 2018; Derin et al. 2016; Hirpa et al. 2010; Dinku et al. 2008; Timmermans et al. 2019; Beck et al. 2019; Ebert et al. 2007; Tian and Peters-Lidard 2010; Sun et al. 2018; Dinku et al. 2010). While a few studies have examined sub-10-km, hourly QPE over flat terrain in limited areas (e.g., Anagnostou et al. 1999; Habib and Krajewski 2002; Seo and Krajewski 2010), to our knowledge, the uncertainty of hourly precipitation products that are available for the continental United States (CONUS) and beyond at grid spacings on the order of a few kilometers has not yet been explored, possibly because the uncertainties at lower resolutions and longer accumulation periods are 
TABLE 1. List of datasets used in the study, with native spatial and temporal resolution and primary observation type.

\begin{tabular}{lccc}
\hline \multicolumn{1}{c}{ Dataset name } & Spatial resolution & Temporal resolution & Type \\
\hline CMORPH & $8 \mathrm{~km}$ & $30 \mathrm{~min}$ & Satellite-based \\
IMERG & $0.1^{\circ}$ & $30 \mathrm{~min}$ & Satellite-based \\
PERSIANN & $0.04^{\circ}$ & Hourly & Satellite-based \\
GSMaP & $0.1^{\circ}$ & Hourly & Satellite-based \\
HADS gauges & Point & Hourly & Gauge \\
HMT gauges & Point & Hourly & Gauge \\
MRMS Gauge-Adjusted & $1 \mathrm{~km}$ & Hourly & Gauge-adjusted radar \\
MRMS Mountain Mapper & $1 \mathrm{~km}$ & Hourly & Climatology-adjusted gauge \\
RTMA & $2.5 \mathrm{~km}$ & Hourly & Multisensor \\
URMA & $2.5 \mathrm{~km}$ & Hourly & Multisensor \\
\hline
\end{tabular}

known to be large. Operational entities in this region such as the NWS and California Nevada River Forecast Center (CNRFC) rely heavily on gauge-based QPE adjusted for orographic effects, such as Precipitation-Elevation Regressions on Independent Slopes Model (PRISM; Daly et al. 1994, 2017) for forecast evaluation on scales from several hours to daily. However, it is important within the context of the AQPI project to understand the behavior of various QPE products at resolutions of interest to AQPI stakeholders, which range from event totals down to subhourly and grid spacings of a few kilometers, which are necessary for accurate representation of surface hydrologic processes in complex terrain (Chen et al. 2019). Understanding the performance of existing high-resolution QPE datasets can then inform how new observations are used and how the experimental quantitative precipitation forecasts (QPFs) can be evaluated. Our goal in this study is not to compare each individual dataset to a given "reference," but rather to examine the uncertainty in high-resolution QPE when considering multiple datasets with an eye toward accounting for this uncertainty when evaluating forecast model performance.

\section{Datasets}

In this study we evaluate gridded precipitation products from a variety of sources, with the requirement that they are available at hourly time steps and a spatial resolution of $10-\mathrm{km}$ grid spacing or less. Because we are interested in potentially using these products for validation of highresolution $\mathrm{QPF}$, we linearly interpolate all products to a $3-\mathrm{km}$ grid to match that of the operational High Resolution Rapid Refresh (HRRR; Benjamin et al. 2016) model using the scipy.interpolate package in Python. We assess several different types of QPE datasets, acknowledging that each has its own strengths and weaknesses. Included are four satellite-based products, two gauge datasets, two gauge-informed products, and two multisensor products. The four satellite products are the NOAA Climate Prediction Center (CPC) morphing technique
(CMORPH; Joyce et al. 2004; Xie et al. 2017) version 1.0, Integrated Multisatellite Retrievals for GPM (IMERG) version 6 research/final run (Huffman et al. 2018), Precipitation Estimation from Remotely Sensed Information Using Artificial Neural Networks-Cloud Classification System (PERSIANN-CCS; Hsu et al. 1997; Hong et al. 2004), and Global Satellite Mapping of Precipitation (GSMaP; Kubota et al. 2007; Ushio et al. 2009). The two gauge datasets are the Hydrometeorological Automated Data System (HADS; Kim et al. 2009) and gauges operated in the region as part of the Hydrometeorology Testbed-West (HMT). The gaugeinformed products are the Mountain Mapper (MM) and Gauge-Adjusted Radar (GA) from the Multi-Radar Multi-Sensor (MRMS; Zhang et al. 2011, 2014, 2016) QPE. The two multisensor products are produced by the National Centers for Environmental Prediction (NCEP) and include the Real Time Mesoscale Analysis and Unrestricted Mesoscale Analysis [RTMA (De Pondeca et al. 2011) and URMA, respectively]. Stage IV, a 4-km multisensor QPE product frequently used in precipitation verification studies (Lin and Mitchell 2005; Nelson et al. 2016) was not included in the full evaluation because hourly QPE from the CNRFC has not been included in the Stage IV product since 2016. Brief descriptions of the products follow and are summarized in Table 1.

Gaps in data availability were minimal for the satellite-based products, and gaps for multisensor datasets ranged from $16 \%$ of hours for RTMA, approximately $5 \%$ for MRMS products, and less than $1 \%$ for URMA. Missing gauge data varied by gauge location, with most sites missing less than $10 \%$ of hours. No attempt was made to interpolate precipitation estimates during periods of missing data.

\section{a. Satellite-based products}

\section{1) CMORPH VERSION 1.0}

The CMORPH technique allows for the combination of instantaneous precipitation estimates retrieved from 
multiple passive microwave instruments flown on lowEarth-orbiting (LEO) satellite platforms into a global precipitation estimate. A given location may only experience a small number of LEO overpasses per day, so in order to produce precipitation estimates between LEO overpasses, consecutive images from geostationary infrared (GEO-IR) satellite data are used to estimate motion vectors and changes of size of precipitation features. Using this information, timeweighted interpolation is performed both forwards and backward in time between LEO overpasses, determining the shape and location of the precipitation field during periods with no passive microwave observations. This is referred to as the "morphing" process (Joyce et al. 2004). In version 1.0, the entire CMORPH dataset is reprocessed and extended to cover the period from 1998 to present. The reprocessing includes a bias correction using CPC gauge-based analysis of daily precipitation (Xie et al. 2017).

The CMORPH product is available half-hourly, at $\sim 8$-km grid spacing over the globe. To obtain an hourly precipitation estimate for the purposes of this study, each half-hourly rain rate estimate is assumed constant for the entire half hour (e.g., a $1 \mathrm{~mm} \mathrm{~h}^{-1}$ rain rate estimate over $30 \mathrm{~min}=0.5 \mathrm{~mm}$ of accumulated precipitation during that time), and each 30 -min estimate is accumulated to obtain the hourly precipitation.

\section{2) PERSIANN-CCS}

PERSIANN-CCS is developed by the Center for Hydrometeorology and Remote Sensing at the University of California, Irvine. In the PERSIANN-CCS algorithm, cloud features are categorized based on height, areal extent, and texture estimated from GEO-IR imagery. These classifications are then used to help assign a rain rate to each pixel within the cloud feature based on a regionally dependent and temporally evolving empirical relationship between rain-rate and brightness temperature that was developed for each class of cloud. The cloud classification system and precipitation distribution for each cloud type was developed and trained for an artificial neural network using surface radar and observations from the Tropical Rainfall Measurement Mission (TRMM) satellite (Hsu et al. 1997; Hong et al. 2004).

PERSIANN-CCS precipitation estimates are produced at a variety of time scales ranging from hourly to annually, and are available at $0.04^{\circ}$ grid spacing (approximately $4 \mathrm{~km}$ ) covering the area from $60^{\circ} \mathrm{N}$ to $60^{\circ} \mathrm{S}$.

\section{3) IMERG V06}

The IMERG algorithm intercalibrates, merges, and interpolates precipitation estimates from as many LEO microwave instruments as possible, and includes microwave-calibrated estimates from infrared satellites as well as gauge analyses for the final run. The production algorithm takes advantage of the wide range of expertise the U.S. satellite precipitation community has developed and represents a collaboration of existing methodologies. First, the microwave precipitation estimates are intercalibrated to account for differences in scan strategy, overpass times, and available channels on each LEO instrument. The microwave estimates are then interpolated temporally using CMORPH, which is also used, in conjunction with PERSIANN to fill gaps with microwave-calibrated IR estimates. Finally, monthly gauge data from a variety of sources is used to reduce bias (Huffman et al. 2018).

IMERG provides gridded precipitation estimates at $0.1^{\circ}$ grid spacing $(\sim 10 \mathrm{~km})$ every $30 \mathrm{~min}$ from $60^{\circ} \mathrm{N}$ to $60^{\circ} \mathrm{S}$. Hourly precipitation is calculated in the same way as for CMORPH. IMERG products are produced with different latencies to allow for near-real-time dissemination as well as monthly gauge-based bias correction. Here we use the final run that incorporates the bias correction for the highest quality possible, although for rapid response applications relevant to AQPI partners the near-real-time product might be more appropriate.

\section{4) GSMAP V7}

GSMaP is produced by the Japanese Aerospace Agency (JAXA) and is similar to CMORPH in that it combines precipitation estimates from passive microwave radiometers on LEO satellites with motion vectors from GEO-IR (Ushio et al. 2009; Kubota et al. 2007). It also incorporates a Kalman filter technique to use cloud-top height measurements from the GEO-IR to estimate changes in precipitation intensity that occurs both forward and backward in time in between LEO overpasses. GSMaP is available at $0.1^{\circ}$ hourly from $60^{\circ} \mathrm{N}$ to $60^{\circ} \mathrm{S}$.

\section{b. Independent gauge data}

\section{1) HADS}

The HADS dataset includes approximately 7000 gauges operated by a variety of state and federal agencies (Kim et al. 2009). Data from each gauge are transmitted to the HADS program office, where it is processed and archived. The incoming data from each agency are monitored for obvious issues such as instrument malfunction or transmission errors; however, stringent quality control is not performed and is left to the end user. As part of the processing, observations are confirmed to be valid at the top of the hour, and if missing values can be proven to have occurred when no rain was present, they are replaced in the data with 
zeros. HADS data are archived at the National Centers for Environmental Information (NCEI). Gauges that are included in the HADS network may be used to bias correct or create other QPE products included in this study.

For the purposes of this study, HADS point gauge data are not interpolated to cover the entire domain grid, and no additional quality control is performed. Gauges are assumed representative of the $3-\mathrm{km}$ grid box they occupy, and if more than one gauge occupies a grid box, the grid box value represents the average hourly precipitation from those gauges. The location of 231 HADS gauges within the AQPI domain is shown by gray plus signs in Fig. 1 and represents an average gauge density of one gauge per $767 \mathrm{~km}^{2}$.

\section{2) HMT-West}

The Physical Sciences Laboratory (PSL) at NOAA's Earth Systems Research Laboratory (ESRL) operates a number of rain gauges in the western United States as part of the NOAA Hydrometeorological Testbed. Although fewer in number than the HADS gauges, the HMT network provides an additional source of precipitation information in areas where other in situ measurements might not be available and represents a completely independent network that is not used for gauge adjustment of any other QPE products evaluated in this study. Many of the 49 gauges found in the AQPI domain were sited with the purpose of monitoring precipitation interactions with the terrain. For example, 25 gauges are concentrated in the Russian River basin, just north of the San Francisco Bay, while 8 are located in the American River basin above Folsom Lake. Several of the HMT-West gauges are collocated with vertically pointing radars. The gauges are maintained by PSL staff and are shown by black dots in Fig. 1. Gauges were removed from consideration during periods with known issues (telemetry problems or stuck gauge).

\section{c. $M R M S$}

MRMS products are produced at NCEP and distributed to NWS forecast offices and other agencies. MRMS combines precipitation estimates from a variety of sensors and observational networks to produce hourly precipitation estimates over the CONUS on a 1-km grid (Zhang et al. 2011, 2014, 2016). Input datasets include U.S. and Canadian operational radar networks, HADS gauge data with additional quality control as described by Qi et al. (2016), PRISM (Daly et al. 1994, 2017), and environmental output from numerical weather prediction models. There are four separate MRMS QPE products incorporating different input data or combinations thereof: radar only, gauge only, Gauge-Adjusted
Radar, and Mountain Mapper. We focus here on the evaluation of the products that include multiple types of precipitation information: Gauge-Adjusted Radar and Mountain Mapper, which have been shown to perform more favorably in the region than the Radar Only and Gauge Only products (Willie et al. 2017).

\section{1) MRMS GAuge-AdJusted RADAR}

The MRMS Gauge-Adjusted Radar product uses reflectivity data from the U.S. WSR-88D network and C-band radars from Environment Canada. As discussed, weather radar data is not always reliable in the western United States due to beam blockage and inadequate coverage (Fig. 1), in addition to the systematic uncertainties typical of radar-based QPE. To try to account for these uncertainties, the MRMS algorithm identifies different precipitation types that are assigned one of five different $Z-R$ relationships (Zhang et al. 2016), employs a radar quality index to determine where radar data may not be reliable, and uses dual-polarization variables to filter out nonprecipitation echoes.

The radar-based estimates of precipitation are then adjusted using data from the HADS gauge network. The adjustments are calculated at the gauge sites, and then interpolated to the 1-km MRMS grid using inverse distance weighting before being applied over the whole domain.

\section{2) MRMS MOUNTAIN MAPPER}

The MRMS Mountain Mapper product does not include radar. This product's algorithm interpolates the HADS rain gauge data using inverse distance weighting, and then adjusts for orographic enhancement using the PRISM climatology (Daly et al. 1994, 2017). PRISM uses an elevation model to calculate linear relationships between precipitation and elevation at monthly and annual scales. These relationships are then applied to the interpolated HADS data to produce orographically enhanced precipitation in the Mountain Mapper product.

\section{d. RTMA and URMA}

In 2004, the NWS established a multiphase program to build a "Reanalysis of Record" to provide high spatial and temporal reanalyses over an approximately 30-yr period. The RTMA represents the first phase of this program (De Pondeca et al. 2011). RTMA produces two-dimensional variational (2DVAR) analyses of 2-m temperature, specific humidity, and dewpoint as well as 10-m $U$ and $V$ wind components using hourly forecasts from the 13-km Rapid Update Cycle (RUC) model as a first guess. RTMA precipitation estimates are produced by bilinearly interpolating the "early" version of the 


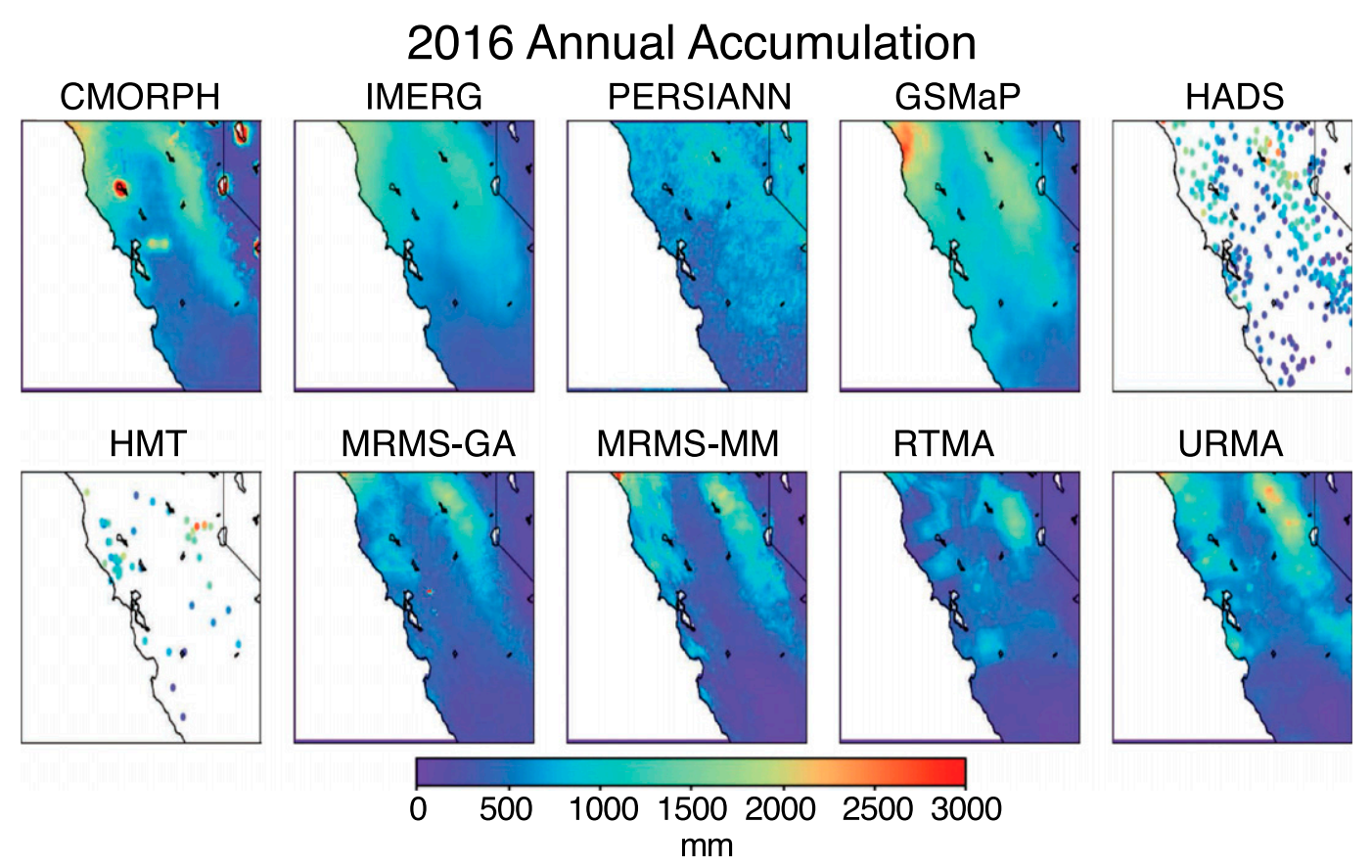

FIG. 2. Annual accumulation of precipitation from calendar year 2016 at 3-km grid spacing for the 10 QPE datasets considered.

NCEP stage II multisensor hourly precipitation analysis onto the $2.5-\mathrm{km}$ RTMA grid. The early stage II analysis is composed of data from $150 \mathrm{WSR}-88 \mathrm{D}$ operational radars and gauge data from approximately 1500 Automated Surface Observing System (ASOS) stations and is produced by NCEP at 35 min past each hour. URMA precipitation analyses are produced later, using additional data not available at the time of RTMA production.

\section{Results}

After all of the candidate datasets have been interpolated to $3-\mathrm{km}$ grid spacing and hourly temporal resolution, we compared QPE over land from each of the datasets in a variety of ways. While the focus of this paper is to examine the hourly precipitation uncertainty, it is a useful exercise to examine product behavior at longer time scales. Previous studies have examined accumulation periods ranging from $3 \mathrm{~h}$ to annual, however the majority have focused on much lower spatial resolution on the order of $0.25^{\circ}$.

Figures 2 and 3 show the annual precipitation from each of the high-resolution QPE products for calendar years 2016 and 2017, respectively. Looking at two consecutive years of precipitation estimates illustrates the large interannual variability of precipitation in the AQPI domain and highlights systematic behaviors of individual QPE products. All of the products appear to agree that 2017 was a wetter year than 2016. The largest year to year difference is in the Sierra Nevada and is most evident in the datasets that have the highest native spatial resolution (MRMS, URMA, and gauges). The satellite-based products typically have a lower signal of orographic enhancement than the products that include groundbased sensors. In fact, IMERG and PERSIANN-CCS do not capture the topographic signal at all. CMORPH and GSMaP have increased accumulations over the terrain, but to a lesser magnitude than the groundbased multisensor and gauge products. The GSMaP precipitation maxima are also in distinctly different locations than the other products. While most products show a precipitation maximum for both years in the Sierra Nevada above Lake Oroville, the maximum annual precipitation from GSMaP is located to the south of Lake Tahoe. Although the products, with the exception of GSMaP seem to mostly agree on the general location of the annual precipitation maximum, they disagree on the magnitude. The disagreement is larger in 2017 than 2016, where in 2017 annual accumulations in the Sierra Nevada differ by over $1000 \mathrm{~mm}$ between the products.

Several artifacts are obvious in the CMORPH, MRMS, RTMA, and URMA products. CMORPH appears to have an issue over large bodies of water, producing significant precipitation maxima over and around them. This is possibly due to the microwave emissivity model in the retrieval interpreting the lower-emissivity water bodies as cold clouds. In the 


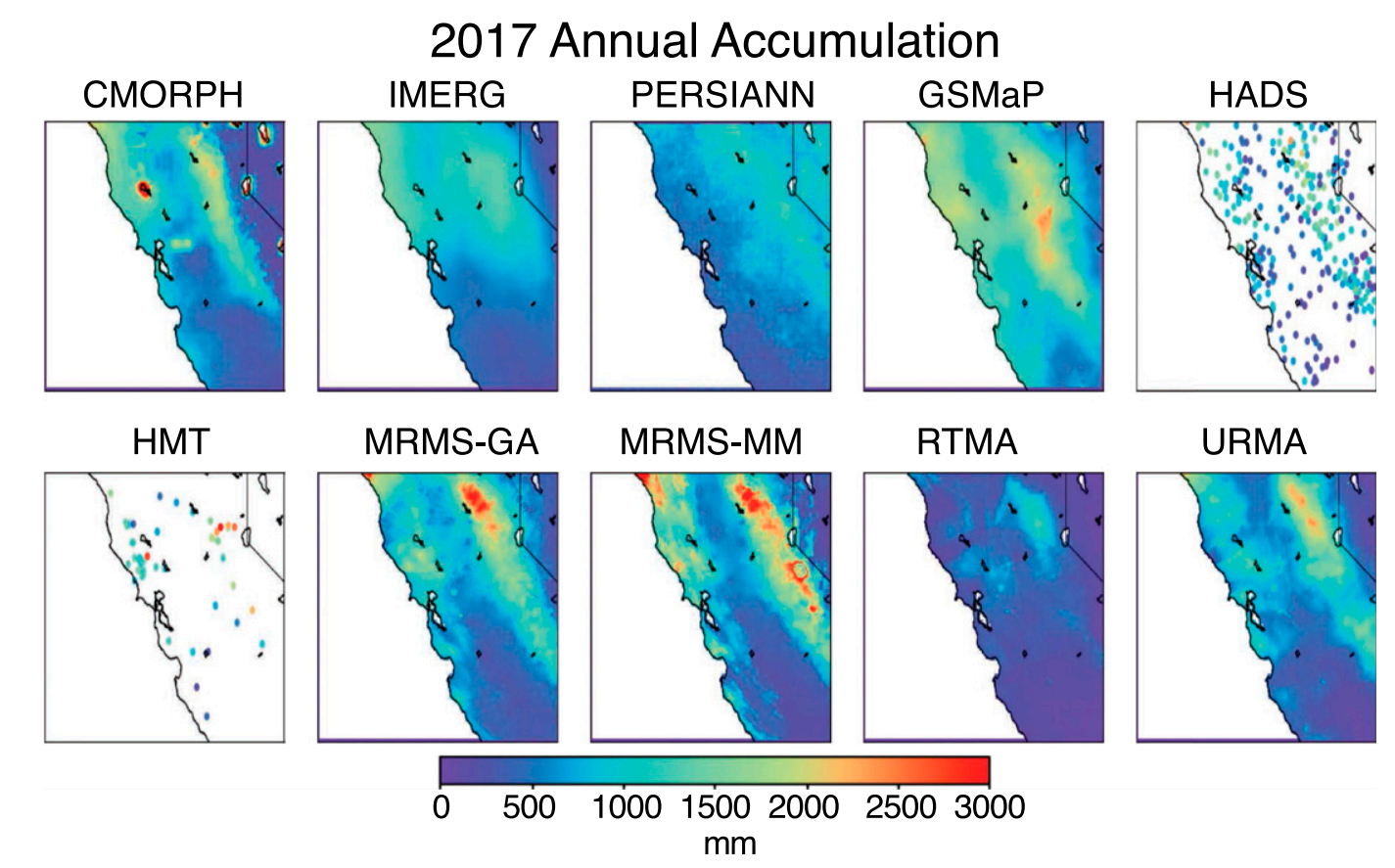

FIG. 3. As in Fig. 2, but for calendar year 2017.

RTMA, URMA, and MRMS Gauge-Adjusted products, there are clearly artifacts related to the use of radar. In 2016, the MRMS Gauge-Adjusted product has a maximum just west of the Bay Area associated with a large wind farm, which appears to have been at least partially accounted for in 2017. Range rings where a given radar's radius of influence ends are evident in the RTMA, and to a lesser extent URMA. The MRMS Mountain Mapper product appears to include several erroneous gauge stations just south of Lake Tahoe, as evidenced by a large ring of enhanced precipitation in Fig. 3. When looking at maps of monthly accumulations (not shown), this feature seems to only be a problem during the months of March and April. This is likely due to a quality control issue and is intended to be corrected with the next version of the MRMS (S. Martinaitis 2019, personal communication). Figures 2 and 3 also illustrate the relative scarcity of gauge measurements in the AQPI domain, particularly as one gets farther south; the gauge locations are enlarged during plotting for easier viewing, which downplays the inadequate gauge availability.

Figure 4 shows the 2016 and 2017 annual accumulations from the operational Stage IV 6-hourly QPE product. East of the Rocky Mountains Stage IV is a multisensor precipitation product that combines radar and rain gauge, however the CNRFC does not use radar in their analysis (Nelson et al. 2016), and so in the AQPI domain it is composed of elevation-adjusted gauge estimates similar to MRMS Mountain Mapper. The Stage IV product shows much higher annual precipitation in both the Coastal Range and Sierra Nevada than any of the products shown in Figs. 2 and 3, with the exception of the northwest corner of the domain, which is consistent with GSMaP in 2016 and MRMS-MM in 2017. Consistency between Stage IV and MRMS-MM is to be expected due to the similarities in production methodology.

There are also significant differences between the products at monthly scales. Figure 5 shows the monthly mean and standard deviation of hourly precipitation from all of the products considered in the domain for January 2017, while Fig. 6 shows the same during August 2017, representing wet and dry months, respectively. Previous studies have shown the performance of QPE, particularly from satellites, to be seasonally dependent, with some finding better performance during the dry season (Derin et al. 2016; Dinku et al. 2010; Beck et al. 2019; Ebert et al. 2007; Tian and Peters-Lidard 2010). As expected, the highest mean hourly precipitation for both months is found over the Sierra Nevada, with the coastal mountains receiving a secondary maximum. The least precipitation falls in the Central Valley, which lies between the Sierra Nevada and Coastal Ranges. The spatial distribution of precipitation in January 2017 is very similar to that found in the annual accumulation maps, which is unsurprising given that the majority of the annual precipitation in this region comes from a few strong storms associated with ARs during the wet season. 


\section{Stage IV Annual Accumulation}
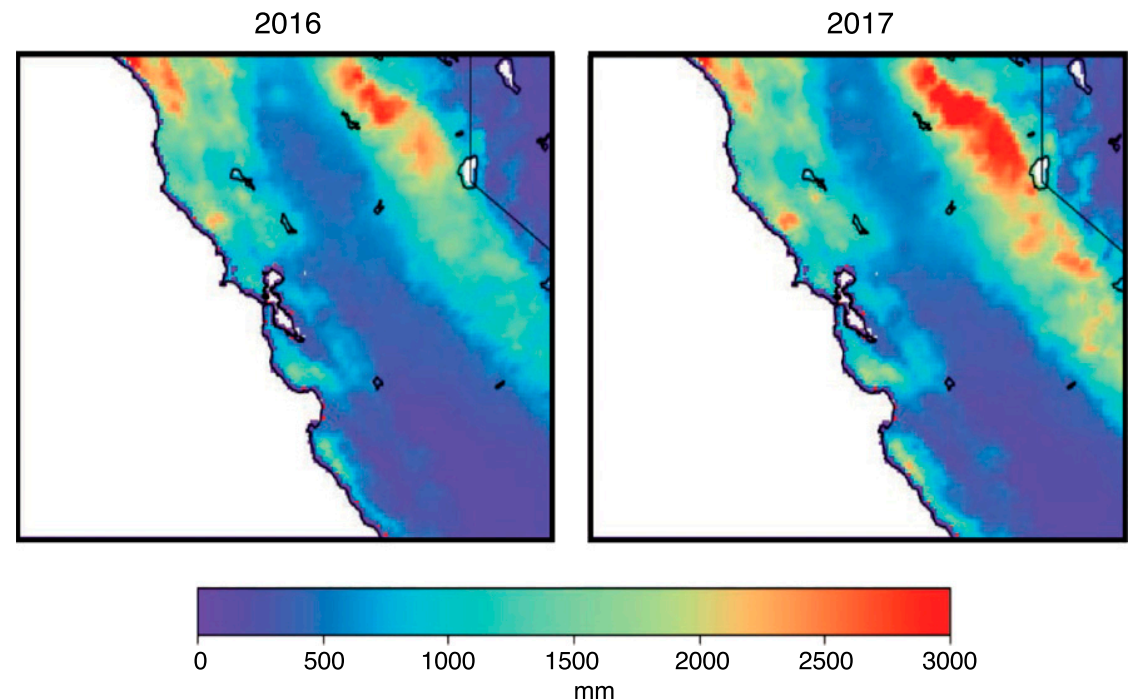

FIG. 4. Annual accumulation of Stage IV product at 3-km grid spacing for 2016 and 2017.

Figure 5 shows that, during January, mean hourly precipitation is around $0.75 \mathrm{~mm}$ over the Sierra Nevada, and closer to $0.25 \mathrm{~mm}$ in the Central Valley. The standard deviation of hourly precipitation during the month of January exceeds $100 \%$ of the mean over much of the domain, even in areas that are relatively well instrumented such as the Central Valley. This highlights the difficulty in obtaining high-resolution precipitation estimates in this region: even where it is relatively well observed, influences of the surrounding terrain make accurate and precise QPE difficult.
Mean hourly precipitation for the month of August 2017 is much less than in January, and in fact is nearly 0 for most of the region. Maximum mean hourly precipitation is in the terrain, where values are approximately $0.12 \mathrm{~mm} \mathrm{~h}^{-1}$. While the maximum in mean hourly precipitation was evenly distributed over the Coastal Range and Sierra Nevada during January, in August the maximum is found only in the central Sierra Nevada south of Lake Tahoe. The lack of strong synoptic scale weather systems and ARs during the dry season likely limits precipitation to occasional orographically induced convection.

\section{January, 2017}

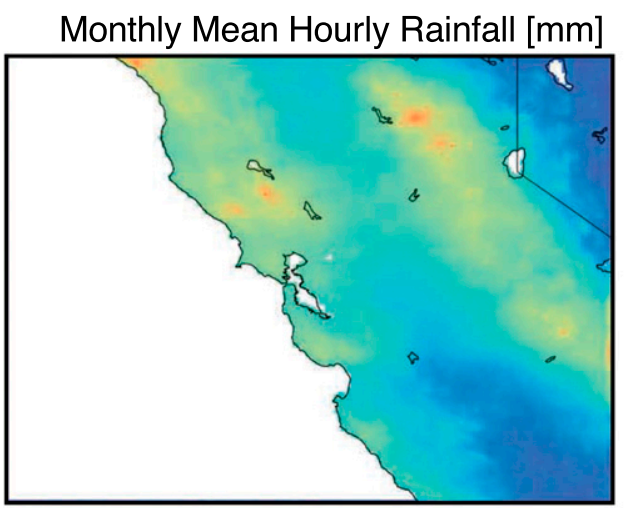

\section{Monthly Mean Hourly Standard Deviation}
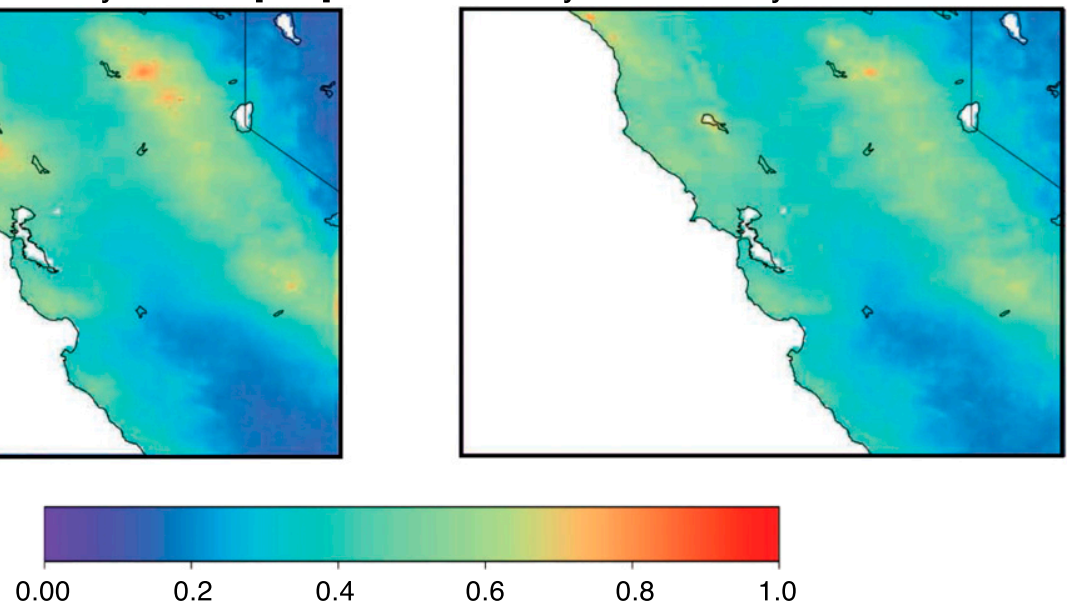

FIG. 5. Mean hourly precipitation and standard deviation for the month of January 2017. 


\section{August, 2017}

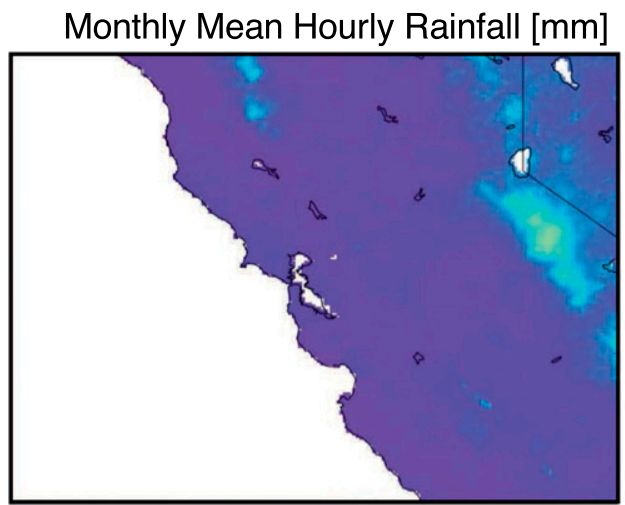

Monthly Mean Hourly Standard Deviation
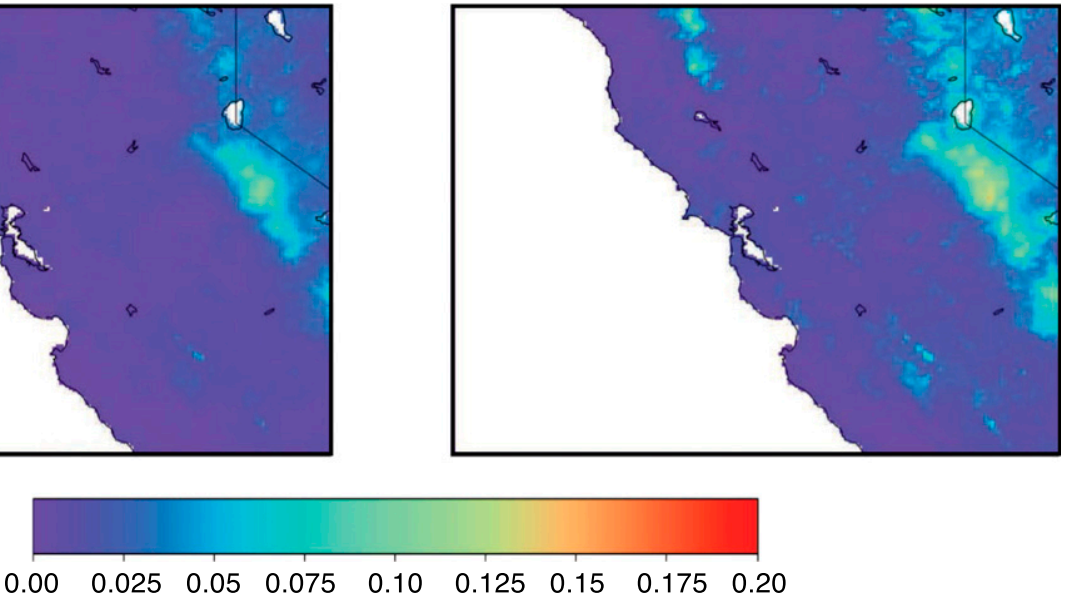

FIG. 6. As in Fig. 5, but for August 2017.

Again, variability among the different QPE products is on the order of, and in some places greater than, the monthly mean hourly precipitation. The large variability between the products during this time of year is possibly compounded by the smaller spatial extent and less temporally coherent nature of orographic convection (i.e., storms that occur between satellite overpasses or do not precipitate over any gauges).

Figure 7 shows the annual cycle of monthly mean, 95th percentile, and standard deviation of precipitation in the AQPI domain for each product during calendar year 2017. Statistics for the HADS and HMT datasets consider only those grid boxes with gauges and the Stage IV product is included for reference. With regard to monthly mean precipitation in the domain (Fig. 7a), nearly all of the products agree as to the general seasonal cycle, that is, having a maximum in January and minimum in the summer months, with additional peaks in February, April, and November. RTMA is the exception, having very low monthly average precipitation during January (and in fact having the lowest domain mean precipitation for most months). URMA compares more similarly to the other datasets, indicating the benefit of incorporating additional observations. The HMT gauges have the highest monthly mean precipitation; however, this is heavily weighted toward locations where gauges are sited, which for this dataset tends to be locations where orographic effects on precipitation are known to be large. GSMaP and HADS also have much higher hourly mean precipitation in the domain in January and February, but fall more in line with the remainder of the products for the rest of the year. Stage IV domain mean monthly rainfall falls in the middle of the products and is generally similar to the MRMS-MM and URMA.

The 95th percentile of monthly precipitation (Fig. 7b) follows a similar pattern to the monthly mean rainfall, with maxima in January, February, April, and November, and most likely represents accumulations found somewhere at higher elevations. Here we see that the products with the least representation of orographic precipitation enhancement in Figs. 2 and 3 (PERSIANN-CCS, IMERG, RTMA, and URMA) have the lowest magnitude 95th percentile monthly precipitation, although URMA and IMERG agree more closely with MRMS-GA during March through May. The 95th percentile of MRMS-MM precipitation is larger than that of the MRMS-GA, illustrating the impacts of adjustment for elevation in the MRMS products. The 95th percentile of Stage IV in January and February is second highest in magnitude. Since these values are likely from high-elevation locations, this is consistent with Stage IV having the highest annual accumulation in the Sierra as shown in Fig. 3.

The spatial standard deviation of monthly mean precipitation is shown in Fig. 7c and is an indication of the spatial variability of precipitation in the domain for each month. This is, as expected, highest during the wet season, when most precipitation occurs and orographic enhancement produces sharp gradients in intensity. Comparing the time series to the annual precipitation maps in Figs. 2 and 3, we can see that the products that have more of a difference between low and high elevations have the highest standard deviations during the wet season (both MRMS, GSMaP, CMORPH, URMA, and Stage IV). The products that do not represent the 

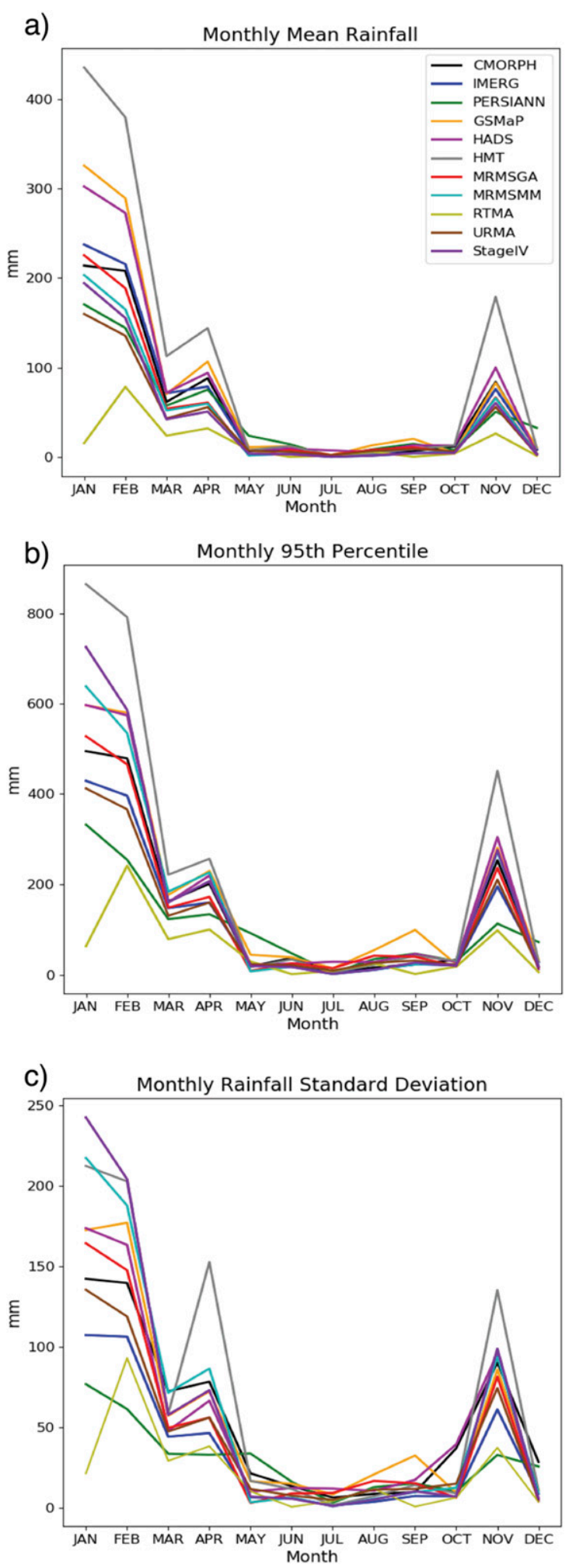

FIG. 7. (a) Mean, (b) 95th percentile, and (c) standard deviation of hourly precipitation over the AQPI domain for each month of 2017. increased precipitation over higher topography on the annual scale have the lowest monthly standard deviations of precipitation.

We now shift our focus to QPE at time scales of interest to the AQPI project, that is, ranging from hourly up to event-total time scales. Figure 8 shows the probability density function (PDF) of nonzero hourly precipitation for each of the products during the 2016-17 calendar years. Again, we see stark differences between the products, some estimating much more light precipitation than others, while some estimate more frequent heavy precipitation. The jumpy appearance of the gauge datasets' PDFs again highlights the relatively small number of nonzero datapoints available even when considering two full years of observations (the remaining datasets' PDFs represent the entire domain and are not subsetted to gauge locations only). In general, the gauge PDFs fall in the middle of the other datasets up to $2.5 \mathrm{~mm}$, then have one of the highest proportions of hourly precipitation between 2.5 and $5 \mathrm{~mm}$, before falling back toward the middle of the pack for higher hourly accumulation amounts. The RTMA and URMA products estimate the highest proportion of light precipitation under $2.5 \mathrm{~mm} \mathrm{~h}^{-1}$ and have the lowest proportion of heavy precipitation. The addition of more in situ observations seems to bring the URMA estimate more in line with the other products, at least for accumulations up to about $4 \mathrm{~mm} \mathrm{~h}^{-1}$. The four satellite products, CMORPH, IMERG, PERSIANN-CCS, and GSMaP have the highest proportion of precipitation $>10 \mathrm{~mm} \mathrm{~h}^{-1}$, with IMERG being most similar to the gauge products for hourly precipitation exceeding $12.5 \mathrm{~mm}$. The two MRMS products track fairly closely, with the MRMS Mountain Mapper product having more very light precipitation $\left(<1 \mathrm{~mm} \mathrm{~h}^{-1}\right)$.

Since the interest of the AQPI stakeholders lies in high-resolution QPE at the hourly time scale, we now examine the uncertainty of the QPE during a heavy precipitation event that took place during February 2017. From 2 to 12 February, the AQPI domain was impacted by several atmospheric rivers that brought significant precipitation to the region (White et al. 2019). Figure 9 shows the mean and standard deviation of hourly accumulation from the 10 QPE datasets over the domain for the hour ending at 1400 UTC 7 February 2017. Over the Bay Area, and stretching eastward toward Lake Tahoe and over the Sierra Nevada, the mean hourly accumulation was approximately $4 \mathrm{~mm}$, with locally higher amounts exceeding $7 \mathrm{~mm}$ in the terrain to the northwest of Lake Tahoe and over Folsom Reservoir. There is also a maximum exceeding $10 \mathrm{~mm}$ just east of Lake Oroville. This maximum presents a bullseye pattern often indicative of gauge artifacts, but it may also be a real signal as the basins above Oroville received significant 


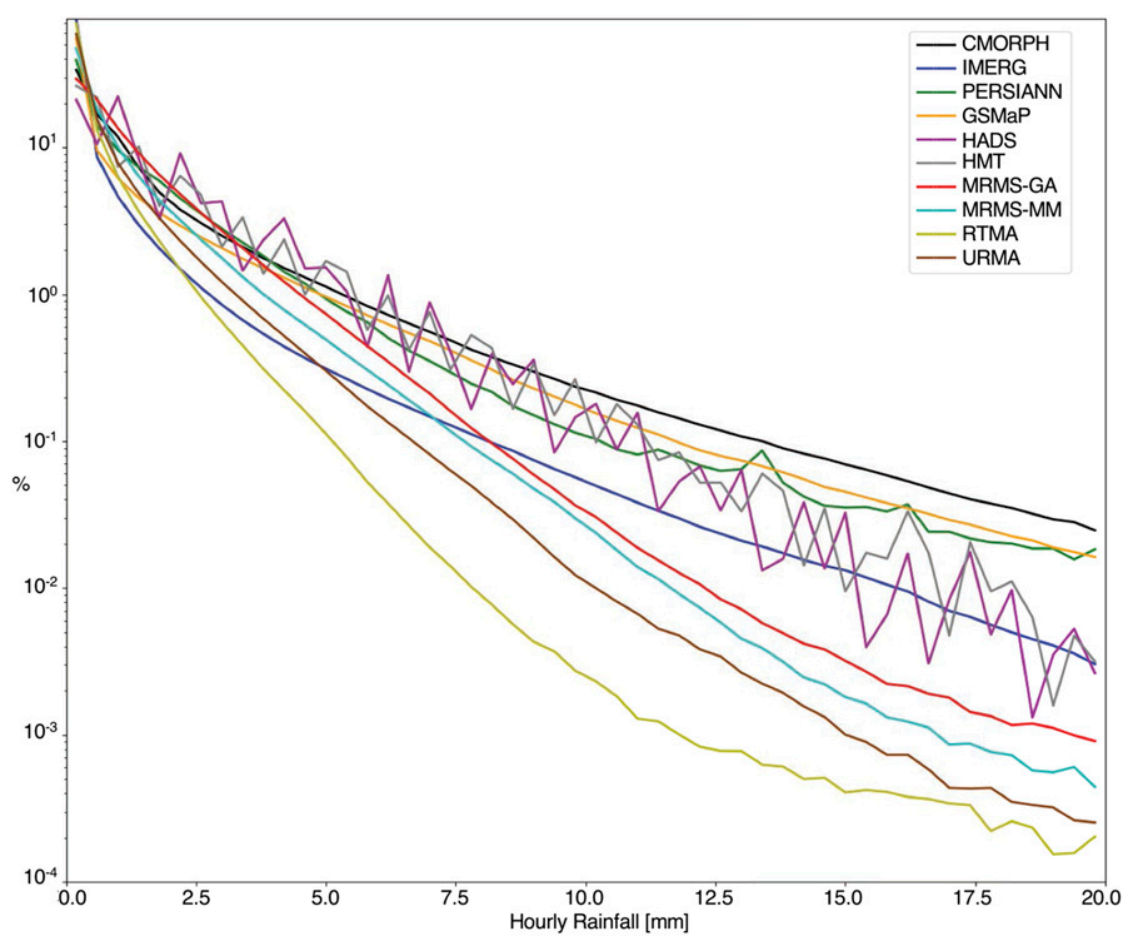

FIG. 8. PDF of nonzero hourly precipitation for 2016 and 2017.

precipitation during this period (White et al. 2019). Similar to the monthly mean hourly precipitation shown in Figs. 5 and 6, the standard deviation of precipitation among the different QPE products exceeds $100 \%$ of the mean during this hour of the storm.

Figure 10 shows mean hourly precipitation in the domain for each dataset during the event. Much like in the annual cycle shown in Fig. 7a, the different datasets seem to agree fairly well in the timing of the heaviest precipitation, but there is substantial disagreement on amount. For all but the final pulse beginning at 1200 UTC 9 February, the HMT gauges have the highest peak mean hourly precipitation, however, as discussed above, this is heavily weighted to gauge

\section{Hour Ending 14 UTC 7 February 2017}
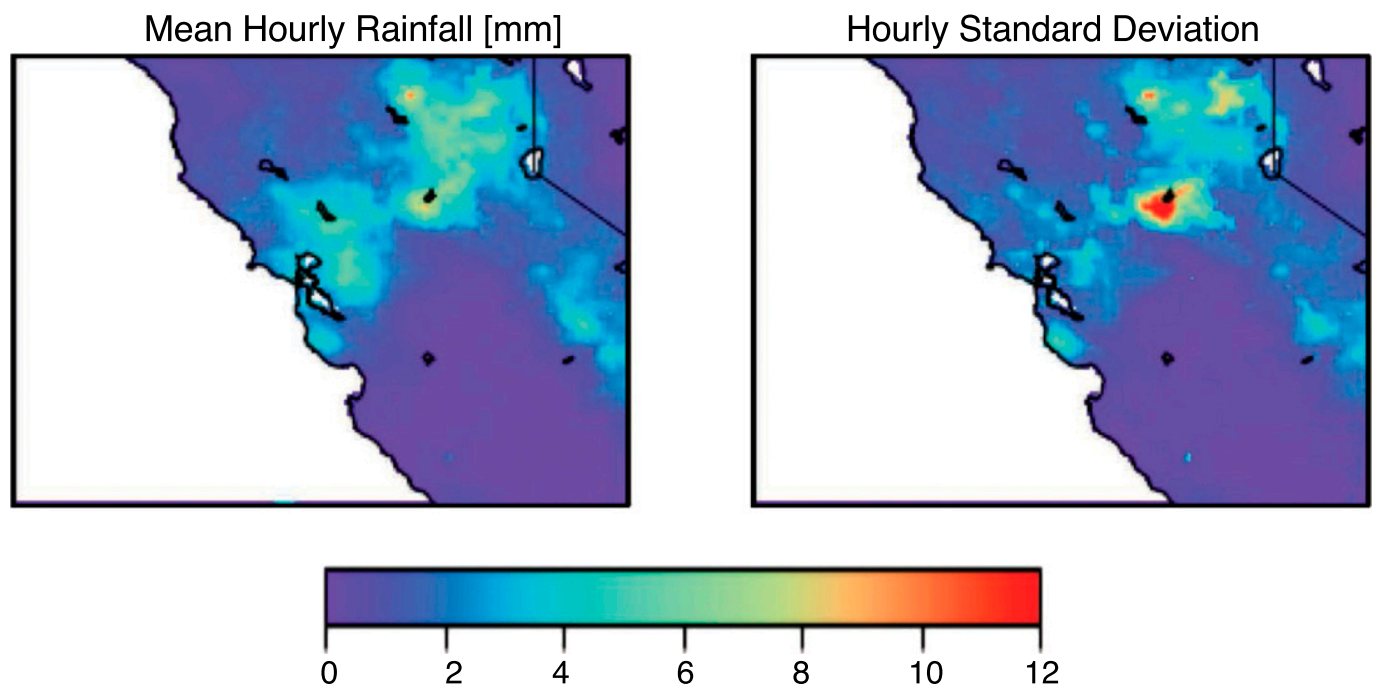

FIG. 9. As in Fig. 5, but for the hour ending 1400 UTC 7 Feb 2017. 


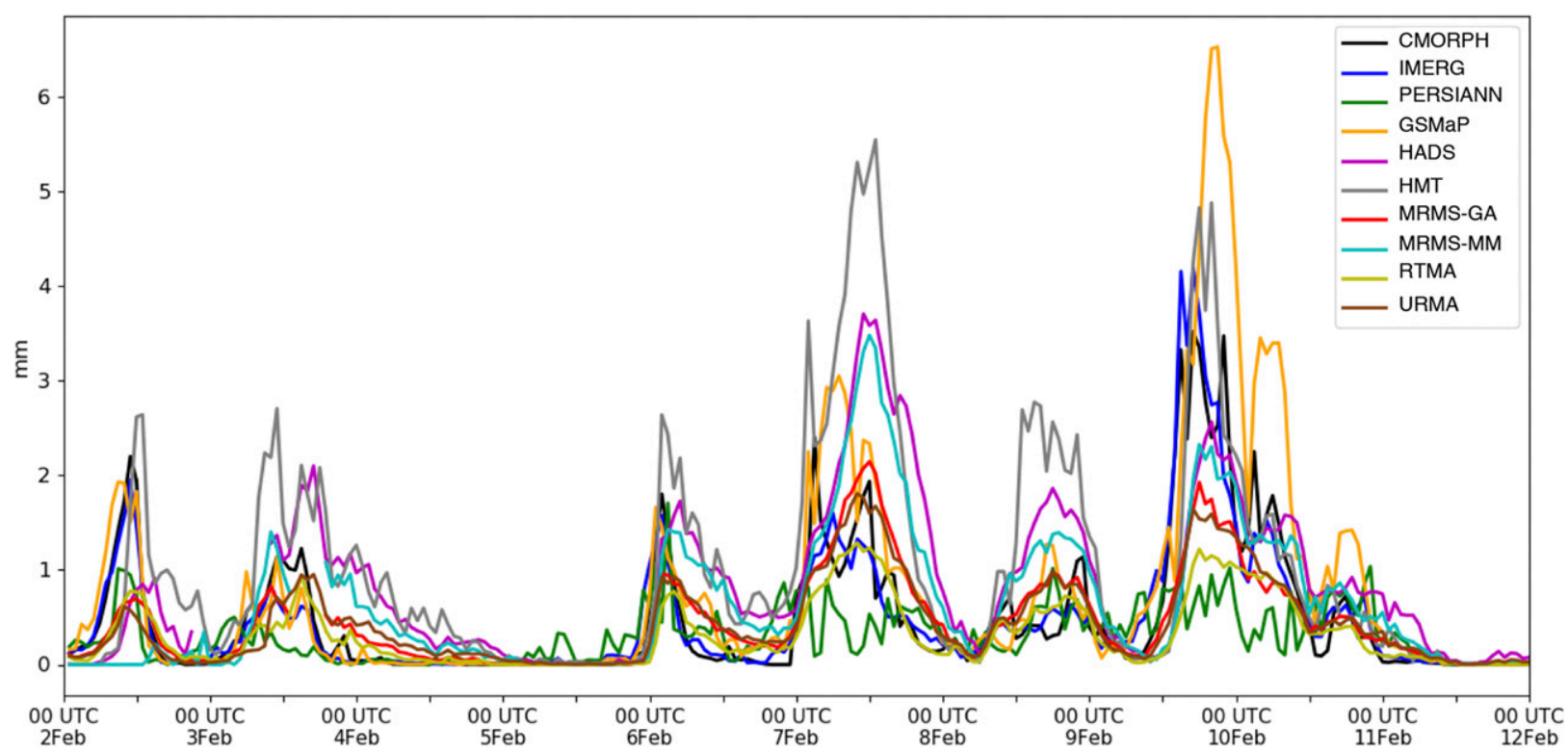

FIG. 10. Mean hourly precipitation in the AQPI domain for the February 2017 event.

locations in areas of orographic enhancement. The HADS gauge dataset and MRMS Mountain Mapper are typically the next highest values, and, along with the HMT gauges seem to report precipitation occurring slightly later or for a longer period of time than the datasets that include remotely sensed observations (radar or satellite). CMORPH, IMERG, and GSMaP indicate earlier onset of precipitation on 2, 6, and 9 February. Meanwhile, on 4, 6, and 8 February, MRMS-GA and URMA indicate precipitation ending later than most of the satellite-based products, but before the gauge-based QPE. These small timing differences likely relate to the challenge of relating remotely sensed cloud properties to surface precipitation. GSMaP interestingly performs similarly to most of the datasets for the first three precipitating periods, as well as the period between 1200 UTC 8 February and 0000 UTC 9 February, but is among the highest estimates during the other two periods of precipitation. PERSIANN-CCS is easily distinguished as the QPE product that estimates the least precipitation in the domain. Some of these behaviors are evident in the event total precipitation maps shown in Fig. 11.

As in the annual accumulation maps shown in Figs. 2 and 3, IMERG and PERSIANN-CCS show very little orographic enhancement of the precipitation (Fig. 11) and have the lowest overall accumulation values. GSMaP also produces a similar pattern to the annual accumulation maps, producing maximum precipitation much higher than the other products and shifted to the south. The remainder of the products place maximum precipitation in the northern Sierra Nevada, though there is disagreement on the magnitude and exact location. The MRMS products place a clear maximum just above Lake Oroville, while the HADS, HMT, RTMA, and URMA products place the maximum to the southeast, between Lakes Oroville and Tahoe. CMORPH, meanwhile, extends the maximum along much of the northern Sierra Nevada, and appears to have a larger contrast between windward and leeward slopes than the other products.

\section{Summary and conclusions}

Accurate, high spatial and temporal resolution precipitation estimates and forecasts are needed for the Bay Area AQPI project to better understand precipitation in the Bay Area and improve precipitation forecasts. This information is crucial for flood mitigation and water management on time scales from hours to a year. The Bay Area and surrounding region of northern California is uniquely challenged by relatively infrequent, but often strong precipitation events that interact with both coastal and inland topography. This topography also tends to block radar observations in many areas, further challenging QPE in this region (Cifelli et al. 2018).

Despite the difficulties, there are still many highresolution ( $\leq 10 \mathrm{~km}$, hourly) gridded QPE products available in this region. All but the HMT gauges are available for large geographic areas, either over the CONUS or globally, and many have been shown to compare favorably to reference datasets in previous studies over larger domains, at degraded spatial resolution, or at long accumulation times. We compared 
Accumulated Rainfall 00 UTC 2 Feb.- 00 UTC 12 Feb. 2017
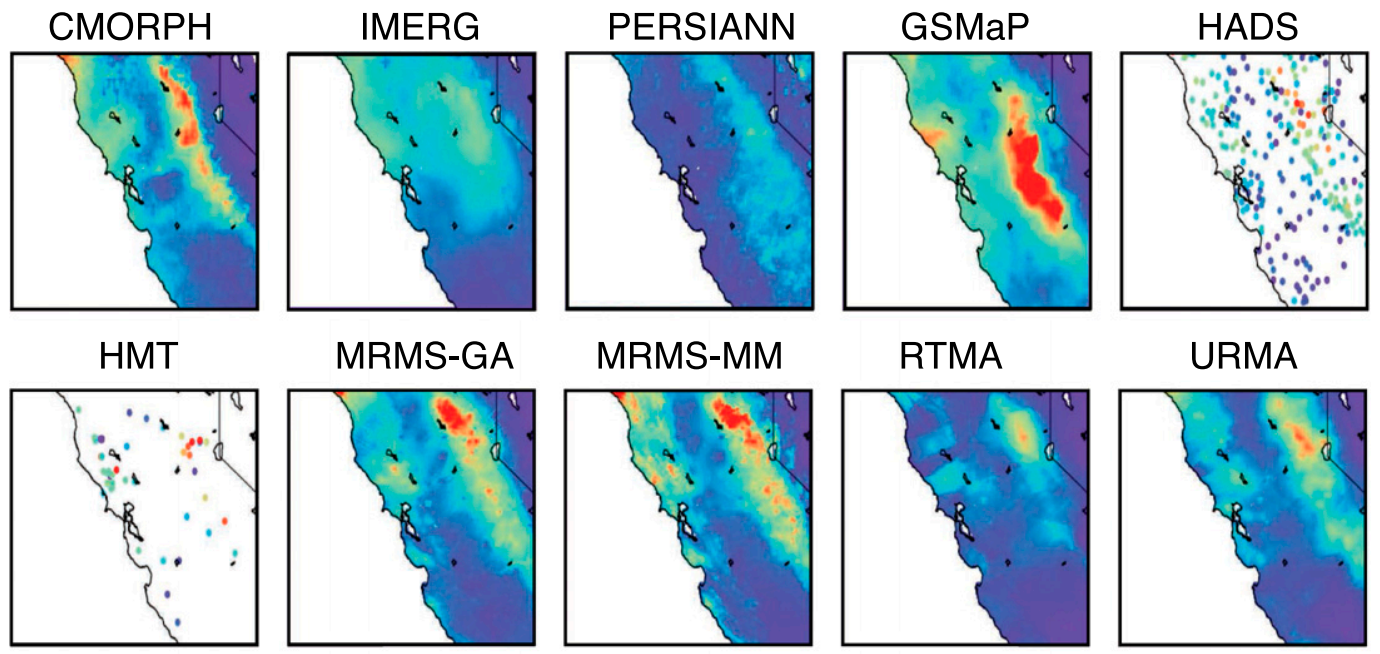

RTMA
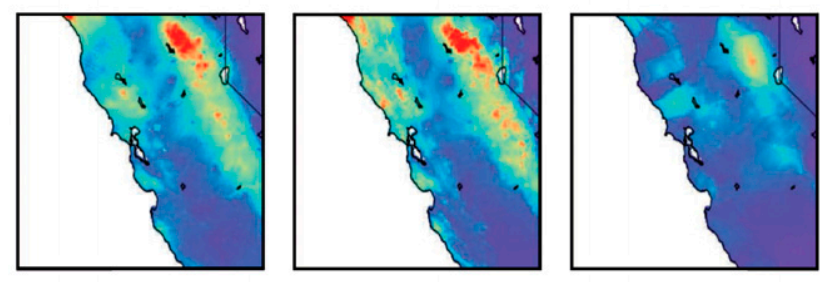

URMA

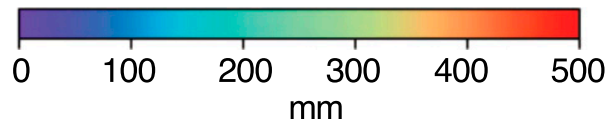

FIG. 11. As in Fig. 2, but for the event lasting from 0000 UTC 2 Feb 2017 through 0000 UTC 12 Feb 2017.

these high-resolution datasets over the AQPI domain at high spatial and temporal resolution, linearly interpolating each to 3-km grid spacing to match the resolution of the HRRR model that produces operational short-term forecasts in the U.S. We calculated statistics for the 3-km QPE fields at annual, monthly, and hourly scales using data covering calendar years 2016 and 2017. Additionally, we provided comparisons to the operational Stage IV analysis at annual and monthly accumulation scales.

Even at annual accumulation times, there were many large differences among the various QPE products. While most had at least some enhanced precipitation over the high terrain, the amount of the increase was highly variable. Previous studies have found that satellite precipitation products tend to underestimate precipitation in areas of high terrain (Bartsotas et al. 2018; Dinku et al. 2008), consistent with the results found herein, particularly for PERSIANN-CCS and IMERG. While the various datasets also tended to agree on the 2017 annual cycle of precipitation, there was more disagreement between the different QPE datasets during the winter wet season than the summer dry season, consistent with results found by Derin et al. (2016), Dinku et al. (2010), Ebert et al. (2007), and Beck et al. (2019). This disagreement is likely compounded by satellite products' difficulty estimating precipitation produced by warm rain processes (Dinku et al. 2010; Derin et al. 2016; Ebert et al. 2007), which occurs often in the atmospheric rivers affecting this region.
At the hourly, 3-km scale of interest to AQPI partner agencies, there is a large variation in the PDF of nonzero hourly precipitation within the region, with frequency of occurrence for hourly precipitation exceeding $2.5 \mathrm{~mm}$ differing by an order of magnitude or more among the different QPE datasets. It is important to remember that not all of these datasets are completely independent: for example, gauges that are part of the HADS dataset also have an influence in the bias correction of CMORPH, IMERG, and MRMS Gauge-Adjusted products, and serve as a basis for the MRMS Mountain Mapper product, yet there are still large differences between the hourly precipitation PDF of each of those datasets. These differences are likely due to the remotely sensed information filling in gauge-less areas and bias correction algorithms and datasets that use different gauges than make up the entire HADS dataset (i.e., using additional gauges not included in HADS, or data that only includes a subset of HADS gauges).

The results in this study illustrate the very difficult task of obtaining accurate high spatial and temporal resolution QPE in regions of complex terrain. The consistent results with previous studies performed at lower resolutions indicate that the challenges of accurate high-resolution QPE are not unique to the Bay Area of California, and such uncertainty in high-resolution QPE can likely be expected in other regions of complex terrain as well. Several of the products examined herein were upscaled from their native resolution to the 3-km HRRR 
resolution, though this generally represents only a slight degradation and in theory would only serve to improve the comparison between products. While the operational forecasters at agencies such as the NWS and CNRFC produce QPE analysis at 4-km spatial resolution, they do not perform QPE analysis or QPF validation at hourly accumulations, nor do they make use of satellite-based QPE products. In the context of the AQPI project, the lower temporal resolutions used by operational agencies are too coarse for many of the stakeholders, and so a main goal of AQPI is to provide improved observations and forecasts of hydrological variables at high spatial and temporal resolutions. Understanding the uncertainty in the existing available high-resolution QPE will help to quantify improvements made by additional observing systems and experimental model forecasts.

Given the large uncertainty in hourly precipitation on the scale of a few kilometers, it is suggested that improving observational capabilities in regions of complex terrain, whether through additional instrumentation, advanced quality control techniques to remove potentially spurious data points (Lundquist et al. 2019), or continued improvement to satellite-based QPE (Utsumi et al. 2019), might be a useful step toward decreasing uncertainty. Additionally, the large uncertainty in highresolution QPE should be considered when using any of the available datasets for forecast validation.

Acknowledgments. Support for this work and for the AQPI project comes from the California Department of Water Resources and NOAA Physical Sciences Laboratory (PSL). Many thanks to Haonan Chen for internal review of this manuscript, and to anonymous reviewers for their comments. Satellite QPE sources were acquired from the following: CMORPH: https://www.cpc.ncep.noaa.gov/products/ janowiak/cmorph_description.html; IMERG: https:// pmm.nasa.gov/data-access/downloads/gpm; PERSIANNCCS: https://chrsdata.eng.uci.edu/. The GSMaP Project was sponsored by JST-CREST and is promoted by the JAXA Precipitation Measuring Mission (PMM) Science Team, and the GSMaP products were distributed by the Earth Observation Research Center, Japan Aerospace Exploration Agency. MRMS data is available from https://www.nssl.noaa.gov/projects/mrms/. RTMA archive is available via the NOAA National Digital Guidance Database. Thanks to Ying Lin for access to archived URMA.

\section{REFERENCES}

Anagnostou, E. N., W. F. Krajewski, and J. Smith, 1999: Uncertainty quantification of mean-areal radar-rainfall estimates. J. Atmos.
Oceanic Technol., 16, 206-215, https://doi.org/10.1175/15200426(1999)016<0206:UQOMAR >2.0.CO;2.

Bartsotas, N. S., E. N. Anagnostou, E. I. Nikolopoulos, and G. Kallos, 2018: Investigating satellite precipitation uncertainty over complex terrain. J. Geophys. Res. Atmos., 123, 5346-5359, https://doi.org/10.1029/2017JD027559.

Beck, H. E., and Coauthors, 2019: Daily evaluation of 26 precipitation datasets using Stage-IV gauge-radar data for the CONUS. Hydrol. Earth Syst. Sci., 23, 207-224, https://doi.org/ 10.5194/hess-23-207-2019.

Benjamin, S. G., and Coauthors, 2016: A North American hourly assimilation and model forecast cycle: The Rapid Refresh. Mon. Wea. Rev., 144, 1669-1694, https://doi.org/10.1175/ MWR-D-15-0242.1.

Chen, X., L. R. Leung, M. Wigmosta, and M. Richmond, 2019: Impact of atmospheric rivers on surface hydrological processes in western U.S. watersheds. J. Geophys. Res. Atmos., 124, 8896-8916, https://doi.org/10.1029/2019JD030468.

Cifelli, R., V. Chandrasekar, H. Chen, and L. E. Johnson, 2018: High resolution radar quantitative precipitation estimation in the San Francisco Bay Area: Rainfall monitoring for the urban environment. J. Meteor. Soc. Japan, 96A, 141-155, https:// doi.org/10.2151/jmsj.2018-016.

Daly, C., R. P. Neilson, and D. L. Phillips, 1994: A statisticaltopographic model for mapping climatological precipitation over mountainous terrain. J. Appl. Meteor., 33, 140-158, https:// doi.org/10.1175/1520-0450(1994)033<0140:ASTMFM>2.0.CO;2.

_ M. E. Slater, J. A. Roberti, S. H. Laseter, and L. W. Swift Jr.., 2017: High-resolution precipitation mapping in a mountainous watershed; Ground truth for evaluating uncertainty in a national precipitation dataset. Int. J. Climatol., 37, 124-137, https://doi.org/10.1002/joc.4986.

De Pondeca, M. S. F. V., and Coauthors, 2011: Real-time mesoscale analysis at NOAA's National Centers for Environmental Prediction: Current status and development. Wea. Forecasting, 26, 593-612, https://doi.org/10.1175/WAF-D-10-05037.1.

Derin, Y., and Coauthors, 2016: Multiregional satellite precipitation products evaluation over complex terrain. J. Hydrometeor., 17, 1817-1836, https://doi.org/10.1175/JHM-D-15-0197.1.

Dettinger, M. D., F. M. Ralph, T. Das, P. J. Neiman, and D. R. Cayan, 2011: Atmospheric rivers, floods and the water resources of California. Water, 3, 445-478, https://doi.org/10.3390/w3020445.

Dinku, T., S. Chidzambwa, P. Ceccato, S. J. Connor, and C. F. Ropelewski, 2008: Validation of high-resolution satellite rainfall products over complex terrain. Int. J. Remote Sens., 29, 40974110, https://doi.org/10.1080/01431160701772526.

_ F. Ruiz, S. J. Connor, and P. Ceccato, 2010: Validation and intercomparison of satellite rainfall estimates over Columbia. J. Appl. Meteor. Climatol., 49, 1004-1014, https://doi.org/ 10.1175/2009JAMC2260.1.

Ebert, E. E., J. E. Janowiak, and C. Kidd, 2007: Comparison of near-real-time precipitation estimates from satellite observations and numerical models. Bull. Amer. Meteor. Soc., 88, 4764, https://doi.org/10.1175/BAMS-88-1-47.

Habib, E., and W. F. Krajewski, 2002: Uncertainty analysis of the TRMM ground-validation radar rainfall products: Application to the TEFLUN-B field campaign. J. Appl. Meteor., 41, 558-572, https://doi.org/10.1175/1520-0450(2002) $041<0558$ :UAOTTG $>2.0 . \mathrm{CO} ; 2$.

Henn, B., A. J. Newman, B. Livneh, C. Daly, and J. D. Lundquist, 2018: An assessment of differences in gridded precipitation datasets in complex terrain. J. Hydrol., 556, 1205-1219, https:// doi.org/10.1016/j.jhydrol.2017.03.008. 
Hirpa, F. A., M. Gebremichael, and T. Hopson, 2010: Evaluation of high-resolution satellite precipitation products over very complex terrain in Ethiopia. J. Appl. Meteor. Climatol., 49, 1044-1051, https://doi.org/10.1175/2009JAMC2298.1.

Hong, Y., K. Hsu, S. Sorooshian, and X. Gao, 2004: Precipitation Estimation from Remotely Sensed Imagery Using an Artificial Neural Network Cloud Classification System. J. Appl. Meteor., 43, 1834-1853, https://doi.org/10.1175/JAM2173.1.

Hsu, K., X. Gao, S. Sorooshian, and H. V. Gupta, 1997: Precipitation Estimation from Remotely Sensed Information Using Artificial Neural Networks. J. Appl. Meteor., 36, 1176-1190, https:// doi.org/10.1175/1520-0450(1997)036<1176:PEFRSI >2.0.CO;2.

Huffman, G. J., and Coauthors, 2018: NASA Global Precipitation Measurement (GPM) Integrated Multi-satellitE Retrievals for GPM (IMERG). Algorithm Theoretical Basis Doc., version 5.2, 35 pp., https://pmm.nasa.gov/sites/default/files/document_ files/IMERG_ATBD_V5.2_0.pdf.

Joyce, R. J., J. E. Janowiak, P. A. Arkin, and P. Xie, 2004: CMORPH: A method that produces global precipitation estimates from passive microwave and infrared data at high spatial and temporal resolution. J. Hydrometeor., 5, 487-503, https://doi.org/10.1175/ 1525-7541(2004)005<0487:CAMTPG > 2.0.CO;2.

Kim, D., B. Nelson, and D.-J. Seo, 2009: Characteristics of reprocessed Hydrometeorological Automated Data System (HADS) hourly precipitation data. Wea. Forecasting, 24, 1287-1296, https://doi.org/10.1175/2009WAF2222227.1.

Kingsmill, D. E., P. J. Neiman, F. M. Ralph, and A. B. White, 2006: Synoptic and topographic variability of Northern California precipitation characteristics in landfalling winter storms during CALJET. Mon. Wea. Rev., 134, 2072-2094, https://doi.org/ 10.1175/MWR3166.1.

Kubota, T., and Coauthors, 2007: Global precipitation map using satelliteborne microwave radiometers by the GSMaP project: Production and validation. IEEE Trans. Geosci. Remote Sens., 45, 2259-2275, https://doi.org/10.1109/TGRS.2007.895337.

Lamjiri, M. A., M. D. Dettinger, F. M. Ralph, and B. Guan, 2017: Hourly storm characteristics along the U.S. West Coast: Role of atmospheric rivers in extreme precipitation. Geophys. Res. Lett., 44, 7020-7028, https://doi.org/10.1002/ 2017GL074193.

Lin, Y., and K. Mitchell, 2005: The NCEP Stage II/IV hourly precipitation analyses: Development and applications. 19th Conf. on Hydrology, San Diego, CA, Amer. Meteor. Soc., 1.2, https://ams.confex.com/ams/Annual2005/techprogram/ paper_83847.htm.

Lundquist, J., M. Hughes, E. Gutmann, and S. Kapnick, 2019: Our skill in modeling mountain rain and snow is bypassing the skill of our observational networks. Bull. Amer. Meteor. Soc., 100 , 2473-2490, https://doi.org/10.1175/BAMS-D-19-0001.1.

Neiman, P. J., F. M. Ralph, G. A. Wick, J. D. Lundquist, and M. D. Dettinger, 2008: Meteorological characteristics and overland precipitation impacts of atmospheric rivers affecting the west coast of North America based on eight years of SSM/I satellite observations. J. Hydrometeor., 9, 22-47, https://doi.org/10.1175/ 2007JHM855.1.

Nelson, B. R., O. P. Prat, D.-J. Seo, and E. Habib, 2016: Assessment and implications of NCEP Stage IV quantitative precipitation estimates for product intercomparisons. Wea. Forecasting, 31, 371-394, https://doi.org/10.1175/WAF-D-14-00112.1.

Qi, Y., S. Martinaitis, J. Zhang, and S. Cocks, 2016: A real-time automated quality control of hourly rain gauge data based on multiple sensors in MRMS system. J. Hydrometeor., 17, 16751691, https://doi.org/10.1175/JHM-D-15-0188.1.

Ralph, F. M., P. J. Neiman, G. A. Wick, S. I. Gutman, M. D. Dettinger, D. R. Cayan, and A. B. White, 2006: Flooding on California's Russian River: Role of atmospheric rivers. Geophys. Res. Lett., 33, L13801, https://doi.org/10.1029/2006GL026689.

, T. Coleman, P. J. Neiman, R. J. Zamora, and M. D. Dettinger, 2013: Observed impacts of duration and seasonality of atmospheric river landfalls on soil moisture and runoff in coastal northern California. J. Hydrometeor., 14, 443-459, https://doi.org/10.1175/JHM-D-12-076.1.

Seo, B.-C., and W. F. Krajewski, 2010: Scale dependence of radar rainfall uncertainty: Initial evaluation of NEXRAD's new superresolution data for hydrologic applications. J. Hydrometeor., 11, 1191-1198, https://doi.org/10.1175/2010JHM1265.1.

Sun, Q., C. Maio, Q. Duan, H. Ashouri, S. Sorooshian, and K.-L. Hsu, 2018: A review of global precipitation data set: Data sources, estimation and intercomparisons. Rev. Geophys., 56, 79-107, https://doi.org/10.1002/2017RG000574.

Tian, Y., and C. D. Peters-Lidard, 2010: A global map of uncertainties in satellite-based preciptiation measurements. Geophys. Res. Lett., 37, L24407, https://doi.org/10.1029/2010GL046008.

Timmermans, B., M. Wehner, D. Cooley, T. O'Brien, and H. Krishnan, 2019: An evaluation of the consistency of extremes in gridded precipitation data sets. Climate Dyn., 52, 6651-6670, https://doi.org/10.1007/s00382-018-4537-0.

Ushio, T., and Coauthors, 2009: A Kalman filter approach to the Global Satellite Mapping of Precipitation (GSMaP) from combined passive microwave and infrared radiometric data. J. Meteor. Soc. Japan, 87A, 137-151, https://doi.org/10.2151/ jmsj.87A.137.

Utsumi, N., H. Kim, F. J. Turk, and Z. S. Haddad, 2019: Improving satellite-based subhourly surface rain estimates using vertical rain profile information. J. Hydrometeor., 20, 1015-1026, https://doi.org/10.1175/JHM-D-18-0225.1.

White, A. B., B. J. Moore, D. J. Gottas, and, P. J. Neiman 2019: Winter storm conditions leading to excessive runoff above California's Oroville Dam during January and February 2017. Bull. Amer. Meteor. Soc., 100, 55-70, https://doi.org/ 10.1175/BAMS-D-18-0091.1.

Willie, D., H. Chen, V. Chandrasekar, R. Cifelli, C. Campbell, D. Reynolds, S. Matrosov, and Y. Zhang, 2017: Evaluation of multisensor quantitative precipitation estimation in Russian River Basin. J. Hydrol. Eng., 22, E5016002, https://doi.org/ 10.1061/(ASCE)HE.1943-5584.0001422.

Xie, P., R. Joyce, S. Wu, S.-H. Yoo, Y. Yarosh, F. Sun, and R. Lin, 2017: Reprocessed, bias-corrected CMORPH global highresolution precipitation estimates from 1998. J. Hydrometeor., 18, 1617-1641, https://doi.org/10.1175/JHM-D-16-0168.1.

Zhang, J., and Coauthors, 2011: National Mosaic and Multi-Sensor QPE (NMQ) system: Description, results, and future plans. Bull. Amer. Meteor. Soc., 92, 1321-1338, https://doi.org/ 10.1175/2011BAMS-D-11-00047.1.

_ - Y. Qi, C. Langston, B. Kaney, and K. Howard, 2014: A real-time algorithm for merging radar QPEs with rain gauge observations and orographic precipitation climatology. J. Hydrometeor., 15, 1794-1809, https://doi.org/10.1175/JHM-D-13-0163.1.

_, and Coauthors, 2016: Multi-Radar Multi-Sensor (MRMS) quantitative precipitation estimation: Initial operating capabilities. Bull. Amer. Meteor. Soc., 97, 621-638, https://doi.org/ 10.1175/BAMS-D-14-00174.1. 